\title{
CONEXÕES NO CINEMA DE APICHATPONG WEERASETHAKUL: POÉTICAS E LINGUAGENS E...
}

\author{
CONNECTIONS IN THE APICHATPONG WEERASETHAKUL CINEMA: \\ POETICS AND LANGUAGES AND...
}

\author{
Pedro Santos Paviotti Vicentin ${ }^{1}$ \\ Marcelo Vicentin ${ }^{2}$ \\ Wagner Gomes Sebastião ${ }^{3}$
}

\begin{abstract}
Resumo: Este artigo se propõe a apresentar os movimentos fronteiriços do cinema de Apichatpong Weerasethakul, movimentos de devires, conexões e alianças por uma imanência antropofágica. Para tanto, nos pautamos pelo encontro do pensamento de Gilles Deleuze e Félix Guattari, e Oswald de Andrade, e os filmes do diretor na emergência de hibridismos e devires que territorializam cartografias outras, singularidades e individuações arbitrárias humanas e não humanas; a potência de uma cinematografia por seus desdobramentos, ressonâncias e contágios...
\end{abstract}

Palavras-chave: Antropofagia; devir; CsO.

\begin{abstract}
This article aims to present the border movements of the cinema of Apichatpong Weerasethakul, movements of becoming, connections and alliances for an anthropophagic immanence. For that, we are guided by the meeting of the thought of Gilles Deleuze and Félix Guattari, and Oswald de Andrade, and the director's films in the emergence of hybridities and becomings that territorialize other cartographies, human and non-human arbitrary singularities and individuations; the power of cinematography due to its consequences, resonances and contagions...
\end{abstract} Keywords: Anthropophagy; devir, CsO.

\section{Cenas iniciais}

Sei apenas que a Tailândia nunca será como as imagens que gostaria de ser: um lugar ultramoderno ou cheio de valores tradicionais. O país inteiro é um animal híbrido. Um animal confuso.

Apichatpong Weerasethakul ${ }^{4}$

Apichatpong Weerasethakul ou dependendo da familiaridade: Joe, Jeuy, Khun Apichatpong ou AW, diretor tailândes, graduado em Arquitetura, mestrado em Belas Artes Cinema pela School of art Institute de Chicago, que transita entre o cinema e as artes visuais. Diretor de 47 filmes entre curtas, médias e longas-metragens (1993-2019), com prêmios nos mais importantes festivais de cinema. Entre os filmes mais conhecidos, o primeiro longametragem, Objeto Misterioso ao Meio-Dia (2000), e Eternamente Sua (2002), Mal dos Trópicos (2004), Síndromes e um Século (2006). Tio Boonmee, Que Pode Recordar Suas Vidas Passadas (2010), Hotel Mekong (2012), Cemitério do Esplendor (2015), Dez Anos na Tailândia (2018).

O cinema de Weerasethakul põe em movimento uma cultura local, exótica aos ocidentais, antihollywoodiana, Por meio de corpos atravessados pelo cotidiano de pessoas comuns alçados a uma

\footnotetext{
${ }^{1}$ Universidade Federal do Espírito Santo. Vitória. E-mail: pedropavioti@gmail.com.

${ }^{2}$ Universidade São Francisco / Universidade Estadual de Campinas. São Paulo. E-mail: marcelovicentin@ yahoo.com.br.

${ }^{3}$ Universidade São Francisco, Campinas. E-mail: wagner.sebastiao@usf.edu.br.

${ }^{4}$ Empurrar e puxar: um intercâmbio com Apichatpong Weerasethakul, p.128.
} 
dimensão política, seu cinema crítica o modelo de modernização da Tailândia, em que as tradições culturais são invadidas pelo desenvolvimento tecnológico, um processo em que a modernidade atua como uma força alienante e alienígena. Aaron Cutler e Mariana Shellard (2014, p. 64) ao analisar a obra do diretor escrevem: "em seus filmes, Apichatpong explora as constantes transformações da Tailândia, seu país natal, onde a natureza e a cultura tradicional confrontam o processo de modernização ditado pela industrialização e pela invasão da cultura ocidental ou se integram a ele".

Nesse movimento conflitante, o cinema de Apichatpong ressoa com antropofagia de Oswald de Andrade e o pensamento de Gilles Deleuze e Félix Guattari, por meio de agenciamentos que problematizam os modelos subjetivos dominantes na lógica da globalização, pela dissolução de subjetividades cristalizadas, emergindo em cena hibridismo e devires que territorializam cartografias outras, singularidades e individuações arbitrárias humanas e não humanas.

As conexões da cinematografia do diretor tailandês com os autores ora citados, aliançam a reterritorialização de experiências sensíveis, que Sueli Rolnik (2000, p. 452453) descreve, como: "engolir o outro [...], de forma que partículas do universo se misturem às que já povoam a subjetividade do antropófago e, na invisível química dessa mistura, se produza uma verdadeira transmutação".

\section{Antropofagias}

A verdade é que a diferença vai diferindo, e que a mudança vai mudando, e que, ao se darem assim como fim de si mesmas, a mudança e a diferença atestam seu caráter necessário e absoluto.

Gabriel Tarde ${ }^{5}$

Deleuze e Guattari (2013) escrevem que para que a filosofia nascesse foi necessário um encontro contingente ou a conjunção de dois movimentos de desterritorialização que se ajustassem ou se conectassem; talvez, de modo menos abstrato, a imagem evocada a Nietzsche, de que "a filosofia seja um emigrado chegado entre os gregos; ocorre assim com os Pré-Platônicos. São de alguma maneira estrangeiros despatriados" (p. 106), pensamento reafirmado pelos autores:

A filosofia foi uma coisa grega, embora trazida por migrantes. Para que a filosofia nascesse, foi preciso um encontro entre o meio grego e o plano de imanência do pensamento. Foi preciso a conjunção de dois movimentos de desterritorialização muito diferentes, o relativo e o absoluto, o primeiro já operando na imanência. Foi preciso que a desterritorialização absoluta do plano de pensamento se ajustasse ou se conectasse diretamente com a desterritorialização da sociedade grega. Foi preciso o encontro do amigo com o pensamento (p. 112)

Paulo Domenech Oneto (2011), argumenta que antropofagia de Oswald de Andrade ressoa com a geofilosofia proposta por Deleuze e Guattari, na afirmação da antropofagia como meio permissivo à emergência e a partição de pensamentos e um modo de operação, um chão conceitual para múltiplos movimentos de desterritorializações e reterritorializações, e não somente para a filosofia, como o mesmo para as artes, aqui, em particular, o cinema de Apichatpong Weerasethakul.

\footnotetext{
${ }^{5}$ Euvres de Gabriel Tarde: monadologie et sociologie, 1895 apud Metafísicas canibais: elementos para uma antropologia pós-estrutural, p. 123.
} 
Rolnik (2000), em "Esquizoanálise e Antropofagia", também se debruça sobre a hipótese de a antropofagia ressoar com o conceito de subjetividade por Deleuze e Guattari.

Estendido para o domínio da subjetividade, o princípio antropofágico poderia ser assim descrito: engolir o outro, sobretudo o outro admirado, de forma que partículas do universo desse outro se misturem às que já povoam a subjetividade do antropófago e, na invisível química dessa mistura, se produza uma verdadeira transmutação. Constituídos por esse princípio, os brasileiros seriam, em última instância, aquilo que os separa incessantemente de si mesmos. Em suma, a antropofagia é todo o contrário de uma imagem identitária.

A ressonância com as ideias de Deleuze e Guattari é notória: a subjetividade, segundo os dois autores, não é dada; ela é objeto de uma incansável produção que transborda o indivíduo por todos os lados. O que temos são processos de individuação ou de subjetivação, que se fazem nas conexões entre fluxos heterogêneos, dos quais o indivíduo e seu contorno seriam apenas uma resultante. Assim, as figuras da subjetividade são por princípio efêmeras, e sua formação pressupõe necessariamente agenciamentos coletivos e impessoais (p. 452-453).

Oneto e Rolnik ecoam conceitos de Deleuze e Guatarri sobre a antropofagia a fim de analisála como um fluxo ou movimento pelo espaço que transborda a uma subjetivação normativa identitária, e, no confronto com um outro, de fora, estrangeiro, partir do princípio de canibalizar para, de acordo com Oneto (2011) devorar o outro para talvez sair de nós mesmos, como uma atitude de desapropriação de si, a fim de deixarmos de ignorar nossas diferenças, e num movimento ético, como argumenta Rolnik (2000), deixar-se afetar pela antropofagia como uma reserva tropical de heterogênese, uma vacina contra a homogeneização de um modelo identitário.

Para tanto, Oneto ressoa a antropofagia sob um plano conceitual que reterritorializa o pensamento para discutir estratégias de invenção social a partir do campo artístico que converge para a geofilosofia, ou estratégias de invenção de subjetividades na produção de sensibilidades que permitem a emergência do pensamento e da produção de efeitos e afetos na paisagem, no território, no solo lamacento e fértil oswaldiano: afirmação para nos atermos a essa lama engendrados em um ato de criação, e, assim, a partir do encontro com o outro, agenciar outros modos de vida e subjetividades.

A meu ver, é justamente isso que significa a noção de 'terra' de DeleuzeGuattari. Em resumo, a terra é esse elemento que nos permite mudar, a lama com a qual entramos em contato paradoxalmente por intermédio do outro, inseparável dos - e irredutível aos - territórios ou meio relativos que se formam (territorialização) e que, justamente, não cessam de ser arrancados de si mesmos (desterritoralização) (ONETO, 2011, p. 6).

Rolnik, também desterritorializa a antropofagia, distanciando-a de uma universalização, não fixando-a a um território, mas reconhecendo sua potência para o efeito de encontros, para multiplicidades de uma máquina de guerra de revoluções moleculares. Potência para agenciamentos entre diferentes reinos antropofágicos, resultando em "processos de individuação ou de subjetivação, que se fazem nas conexões entre fluxos heterogêneos, dos quais o indivíduo e seu contorno seriam apenas uma resultante" (ROLNIK, 2000, p. 453).

Essa aliança permite a crítica e a pulverização de modos de subjetivação associados a um modelo fixo de identidades, e agenciamentos e ressonâncias entre os mais distintos outros, humanos e não humanos. Entretanto, Rolnik (2000) alerta para os perigos presentes, como uma dissolvição identitária que pode acarretar um movimento de homogeneização generalizada. 
Para a autora, a escuta do "Corpo sem Órgãos $(\mathrm{CsO})$ permitiria as conexões entre a antropofagia oswaldiana e a esquizoanálise de Deleuze e Guattari.

Se a interpretamos desta perspectiva, o 'antropo' deglutido e transmutado nessa operação não corresponderia ao homem concreto, mas ao humano propriamente dito - as figuras vigentes da subjetividade, com seus contornos, suas estruturas, sua psicologia. O resultado dessa operação é um desfilar de figuras que se sucedem, geradas nas miscigenações promovidas pelo nomadismo do desejo. Juntando, então, esquizoanálise e antropofagia, diríamos que a lei que rege esse nomadismo é a de um inconsciente maquínico-antropofágico, inumano Corpo sem Órgãos que devora incansavelmente as figuras do humano (p. 455).

Rolnik argumenta que a escuta do $\mathrm{CsO}$ em aliança com a antropofagia nos coloca para além de uma escolha entre o possível e o impossível, mas na emergência de singularidades nos mais diferentes planos, num infinito de agenciamentos que transbordam e desmancham heterogêneses, funcionado como um desinvestimento identitário, de revoluções moleculares. Práticas de forças intensivas, agenciadas pelos aos devires da vida, forças vitais não territorializadas, resistências à homogeneização.

O encontro de Oswald com Deleuze e Guattari, desafia o pensamento estanque de uma de certa governamentalidade essencialista presa a grilhões identitários, deslocando-se do plano da representação. A escuta do $\mathrm{CsO}$ antropofágico atualiza as singularidades, na promoção de outras experiências, encontros potencializadores com modos de vida em trânsito, nômades, que transpõem fronteiras; movimentos territorializantes e desterritorializantes, de contágios e conflitos com forças de conjunto e vizinhança, de absorções e banimentos, de uma nova terra e um povo que não existe ainda, um povo por vir afeito aos afetos da vida, em diálogo com a vida.

\section{A antropofagia de Apichatpong}

Depois que eu devorar a sua alma, não seremos nem animal nem humano. Mal dos Trópicos (2004)

O cinema de Apichatpong Weerasethakul, de acordo Francesca Azzi (2014), são narrativas de um mundo de signos e sintaxe de cinematografia autoral. Cinema que não segue a narrativa clássica com começo, meio, fim; mas imagens que fluem como um rio, com passado e presente se misturando em camadas, misturas de realidade e fantasia, fato e ficção; experimentações fronteiriças nas bordas da reflexão, o silêncio. Nas bordas do campo visual, a exploração do extracampo, de elementos fora da visão do plano: sons, luzes, vultos. Seu cinema trafega pelas fronteiras dos mais diferentes gêneros, causando perplexidade e dificuldade àqueles que pretendem constitui-lo de uma identidade.

Apichatpong explora a hibridez, dinâmicas potências contemporâneas por meio de diversos elementos que situam seu cinema sempre num entre, bem no meio de embaralhamentos, multiplicidades de camadas que nos movimenta, nos põe a pensar. Segundo o diretor, "o cinema que eu construo em trabalhos como Hotel Mekong é uma experiência na fronteira entre a ficção e o documentário, embaralhando diferentes instâncias de percepção de mundo, nas falas, nos movimentos das águas, esfaceladas diante do progresso" (WEERASETHAKUL apud FONSECA, 2014, p. 93). 
Em Objeto Misterioso ao Meio-Dia (2000), a voz extracampo já mistura ficção e realidade na cena inicial: uma mulher traumatizada, relata comovidamente a intenção de seu pai de vendê-la quando criança. Logo após enxugar suas lágrimas, é interpelada pela voz do diretor, que diz: "Agora pode contar outra história, pode ser de um livro ou que você tenha ouvido. Não precisa ser verdade". Essa constante sobreposição de narrativas, com a mistura do real e do encenado, demarca o cinema de Apichatpong, onde tudo se confunde propositalmente: uma estrutura narrativa dando lugar à ausência, deixando que a história se construa coletivamente pelas personagens. Nesta fronteira em que reside o filme, a ficção dá a mão para a realidade e se assumem como uma coisa única, feito animal híbrido, inclassificável. Blocos de imagem que inventam, transformam, conexões entre mundos, nos movimenta por caminhos difíceis, violentos, silenciosos que se repelem ao mesmo tempo em que se fundem; por um cinema de movimentos físicos, cosmológicos, de incontrolável transformação.

Esta desarticulação e heterogenia o faz trafegar entre o local e o global, periferia e o centro, a selva e a cidade, os vivos e os mortos, a ficção e o documentário, devorando referências e as devolvendo por diferentes perspectivas, em que passado, presente e futuro se entrecruzam sob diferentes camadas, rompendo com um tempo linearizado: "era difícil lembrar claramente do passado real, então criei filmes sem saber quão verdadeiros eles realmente eram. Isso era um detalhe importante. Era como acordar os mortos e lhes dar uma nova lama, fazê-los andarem novamente" (WEERASETHAKUL, 2014, p. 102)

Ao trafegar por um pensamento singular, ao invés de uma sucessão de presentes relacionados ao tempo cronológico, cria lençóis do tempo (DELEUZE, 2018) em que ora presente ora o passado expressam imagens diretas do tempo, uma ligação entre o presente e o passado, um jogo de extensão-contração pela coexistência de multiplicidades de passados, e presentes se constituindo. "O que o cristal revela ou faz ver é o fundamento oculto do tempo, quer dizer, sua diferenciação em dois jorros, o dos presentes que passam e o dos passados que se conservam. De uma só vez o tempo faz passar o presente e conserva em si o passado" (p. 145).

O cinema de Apchatpong experiência fraturas no tempo, presente e passados, conforme Daniel Grimberg (2015), sem inícios ou finais definitivos, a fim de subverter uma lógica hegemônica e valorizar a alteridade por meio de policronias alternativas e não normativas, de um presente moderno a um reino mítico ou a-histórico, que lhe permite pluralizar e tornar crível todas as perspectivas apresentadas pelos personagens, ou como argumenta Eduardo Viveiro de Castro (2002) nem explicar, nem interpretar; mas multiplicar, e experimentar.

As rupturas temporais permite ao diretor trabalhar com elementos do mundo concreto, mas não trabalhar com uma representação mimética desse mundo, apenas permitindo que imagem e sons fluam, como as memórias. "Estou interessado em criar determinados ambientes que são reais, mas não em representar a realidade atual. Sobretudo a partir de uma memória de algo passado. Portanto imagino que isso paire entre a realidade imaginada e a realidade" (QUANDT, 2014, p. 138). Weerasethakul alcança com sua arte a mais alta potência do falso (DELEUZE, 2018) não negando o real, porém o desdobrando, desterrritorializando, em permanente experimentação, multiplicação.

Desse modo, em seus filmes o humano é descentrado, desterritorializado, e reterritorializado em territórios não humanos, ocupando o cosmos juntamente com a floresta, os animais, as pedras etc., e, por essa multiplicidade espacial e temporal aliança-se em devires, vive em devir. Michel Foucault (1999), ao escrever sobre a experiência literária, aproxima-a da loucura, de limites que ressoam no encontro com o outro, à experiência de algo absolutamente outro, anárquico, marginal e transgressivo, aquém e além da centralidade cotidiana, o que ocasionaria, segundo ao autor, seu parentesco com a loucura. Deste modo, o cinema de Apichatpong navega nas fronteiras e não somente para a experiência e o encontro com o outro, em que passado e presente confluem, mas 
também para, antropofagicamente, devorar e ser devorado pelo outro, hospedeiro e hospedado, colisão de forças, devires híbridos de homens, animais, fantasmas, uma simbiose e não um processo de produção de identidades, como observado por Castro (2015, p. 186): “o devir é o outro lado do 'espelho da produção:' [...] o avesso de uma identidade: Uma identidade ao contrário, para recordarmos a palavra tupinambá para 'inimigo"”.

Devires de homem-macaco-fantasma, o bagre que faz sexo com a princesa (Tio Boonmee, Que Pode Recordar Suas Vidas Passadas/2010), o tigre-xamã (Mal dos Trópicos / 2004), alianças coms fantasmas que habitam o mundo dos vivos: Huav, a esposa (Tio Boonmee, Que Pode Recordar Suas Vidas Passadas/2010), Pob (Hotel Mekong / 2012) reencarnação que se alimenta de entranhas, bem como a selva, o rio, a força da natureza. Movimentos nas fronteiras, com conexões entre realidade e fantasia, fato e ficção, embaralhando as percepções e sacudindo o evento cinema. Desse modo, ao mergulhar, e nos fazer mergulhar, profundamente em diferentes experiências de aliança com o sobrenatural, as forças da natureza, a floresta, os animais, os mortos, os seres híbridos, dissolve grupos e identidades pela multiplicidade de metamorfoses imaginárias e imanente ao devir; um plano de imanência e uma cartografia de devires e potencialidades.

Todo devir é uma aliança. O que não quer dizer, mais uma vez, que toda aliança seja um devir. Há a aliança extensiva, cultural, sociopolítica, e há a aliança intensiva, contranatural e cosmopolítica. Se a primeira distingue filiações, a segunda confunde espécies, ou melhor, contraefetua por síntese implicativa as diferenças contínuas que são atualizadas, no outro sentido (o trajeto não é o mesmo...), pela síntese limitativa da especiação descontínua. Quando um xamã ativa um devir-jaguar, ele não 'produz' um jaguar, tampouco se 'filia' à descendência dos jaguares: ele adota um jaguar, ele coopta um jaguar - ele estabelece uma aliança felina (CASTRO, 2015, p. 189; grifos originais).

Assim, Apichatpong entre fantasmas e realidade, entre a ficção e o documental, constrói uma delicada trama de reverberações poéticas com dimensões também políticas - não só em seus diálogos, mas até mesmo na lentidão de seus longos planos que, se contrapostos com a freneticidade hollywoodiana, veríamos quase o avesso um-do-outro, uma oposição de linguagem ao cinema dos grandes estúdios americanos:

Em contraste com a estratégia do cinema de Hollywood de incentivar a identificação emocional com os personagens, [... Apichatpong] convida o espectador a partilhar a consciência perceptiva de uma personagem e a vive-la esteticamente, como sensação afetiva. [...] Mas o acesso à sua interioridade subjetiva não provém da empatia com o personagem que vemos, nem sequer de pensar em referências simbólicas ao eu primitivo abstrato [...], mas sim, como sugere Pasolini, de 'permitir que a câmara seja sentida'. As composições longas e meditativas do ambiente natural, e o movimento langoroso da câmera [...], levam o espectador a uma narcose preguiçosa. O idílio da floresta é interpretado como um espaço onírico; a beleza tranquila da paisagem e o zumbido sinfônico da vida de insetos e pássaros mergulham o espectador no que parece ser o sonho derretido antes de dormir. A distensão do tempo produzida no longo plano leva a uma espécie de contemplação flutuante. (MERCER, 2012, p. 196).

\footnotetext{
${ }^{6}$ In contrast to Hollywood cinema's strategy of encouraging emotional identification with characters, [... Apichatpong] invites the spectator to share in a character's perceptual consciousness, and experience it aesthetically, as an affective sensation. [...] But access to his subjective interiority does not come from empathising with the character we see, or even thinking about symbolic references to Min's abstract primeval self, it comes
} 
Esse olhar voltado para o cotidiano, por sua vez, aponta para um gênero de produção no campo do audiovisual que propõe uma outra natureza de narrativas, muito mais subjetiva e sensorial, bastante distinta do cinema industrial, um cinema de entre-lugares, de hibridismo como poética e linguagem, sem uma fronteira clara, conexões que não permitem a estabilização identitária, se situando não mais na pureza do 'ou' encaixotante, mas assumem o advento do 'e' (GONÇALVES, 2014). "E” que de acordo com Deleuze (2017) desequilibra as relações, o ser, o verbo etc.

Nem elemento nem conjunto, o que é o $E$ ? Creio que é a força de Godard, a de viver, de pensar e de mostrar o $E$ de uma maneira muito nova, e de fazê-lo operar ativamente. $O E$ não é nem um nem o outro, é sempre entre os dois, é a fronteira, sempre há uma fronteira, uma linha de fuga ou de fluxo, mas não se vê, porque ela é o menos perceptível. E, no entanto, é sobre essa linha de fuga que as coisas se passam, os devires se fazem, as revoluções se esboçam. [...] De Norte a Sul, sempre serão encontradas linhas que vão desviar os conjuntos, um $E, E, E$ que marca a cada vez um novo limiar, uma nova direção da linha quebrada, um novo desfilar da fronteira. O objetivo de Godard: 'ver as fronteiras', isto é, fazer ver o imperceptível. O condenado $e$ sua mulher. A mãe $e$ a criança. Mas também as imagens $e$ os sons. [...] Sabe-se ao menos que é aí que as coisas passam, na fronteira entre as imagens e os sons, aí onde as imagens tornam-se plenas demais e os sons fortes demais (p. 62-63).

Um cinema que, para Deleuze e Guattari (2013), cria sensações, blocos de sensações formados por perceptos e afectos; constituindo em corpo, operando uma força, uma vibração sobre outro corpo, provocando sensação, desencadeando alguma transformação, colocando movimento em alguém ou algo: um "tornar-se", remetendo a um devir.

É de toda a arte que seria preciso dizer: o artista é mostrador de afectos, inventor de afectos, criador de afectos, em relação com os perceptos ou as visões que nos dá. Não é somente em sua obra que ele os cria, ele os dá para nós e nos faz transformar-nos com ele, ele nos apanha no composto. [...] A arte é a linguagem das sensações, que faz entrar nas palavras, nas cores, nos sons ou nas pedras. A arte não tem opinião. [...] Mas o sucesso de uma revolução só reside nela mesma, precisamente nas vibrações, nos enlaces, nas aberturas que deu aos homens no momento em que se fazia, e que compõem em si um monumento sempre em devir, como esses túmulos aos quais cada novo viajante acrescenta uma pedra (p. 207-209).

Por conseguinte, o cinema de Weerasethakul, um devir, reinventa o conceito de cinema, cria conceitos, faz vibrar e movimentar o pensamento, agencia conexões que faz o pensamento pensar sobre a vida, cria problemas, nos põe a pensar novos pensamentos, põe em evidência e funcionalidade o devir no pensamento, um pensamento em imagens: "É pelo corpo (e não mais por intermédio do corpo) que o cinema se une com o espírito, com o pensamento. 'Dê-me, portanto, um corpo' é, antes de mais nada, montar a câmera sobre um corpo cotidiano" (DELEUZE, 2018, p. 275).

from, as Pasolini suggests, "allowing the camera to be felt". The long, meditative compositions of the natural environment, and the languorous movement of the camera [...] lulls the spectator into a lazy narcosis. The idyll of the forest is construed as an oneiric space; the tranquil beauty of the landscape and the symphonic hum of insect and bird life immerse the spectator into what feels like the dream-melt before sleep. The distension of time produced in the long takes induces a kind of free-floating contemplation. 


\title{
Cenas finais
}

\author{
Cada filme que faço gera uma recepção diferente, \\ inusitada. Algumas pessoas veem o que filmo e \\ compartilham sentimentos. Outras se fecham ao que \\ eu crio. Mas não tento forçá-las a me entenderem", \\ conclui o diretor. \\ Apichatpong Weerasethakul ${ }^{7}$
}

O cinema de Apichatpong Weerasethakul, com seus hibridismos, tornam a vida por multiplicidades de incorporações, de potenciais aventuras e renovações criativas de nossa própria existência, celebrando-a em suas ambiguidades e incertezas, tal qual a antropofagia oswaldiana, afirmando a vida em sua singularidade, em seu devir. Para Rolnik (2000) um pensamento criador e problematizador que desconstrói a homogeneidade e fixidez identitária universal, pois "o inconsciente maquínico-antropofágico não é prerrogativa dos trópicos, e muito menos dos brasileiros: sendo um princípio imanente à produção de subjetividade, ele é próprio da espécie humana como um todo" (p. 462).

Para tanto, o diretor, diferentemente ao cinema "hollywoodiano" e/ou "ocidental" não se ocupa com o "exótico" ou em vender "criaturas de terras estranhas e não civilizadas (WEERASETHAKUL, 2014, 108), pois em seus filmes os espaços, principalmente a selva é lugar para alianças entre as personagens humanas e não humanas, suas histórias, e, também território para outros encontros para os espectadores; espaços desterritorializados ou de devoração para a afirmação na vida.

Territórios onde a linearidade temporal é rompida para que, por múltiplas temporalidades, pela experimentação de singularidades, e, nesse devir, fazer o cinema gaguejar pela ocupação de fronteiras, entre-lugares, híbridos que confundem por que não se aterem a explicar uma realidade, mas em agenciar alianças contingentes entre presente e passados, selva e cidade, tradição e modernidade, humanos e não humanos.

Esse animal híbrido, confuso, e inconcluso, que é o cinema de Apichatpong, é um corpo para encontros com o outro, com o que lhe é estranho, de possibilidades de movimento: "um $\mathrm{CsO}$ é feito de tal maneira que ele só pode ser ocupado, povoado por intensidades. Somente as intensidades passam e circulam" (DELEUZE, 2012, p. 16). Os movimentos cinematográficos do diretor atuam como agenciamentos para uma miríade de universos decorrentes da conexão entre o CsO e a antropofagia, uma estratégia que, de acordo com Rolnik (2000, p. 460) funciona como "uma vacina contra a tendência dominante à homogeneização [...]: a vacina de heterogênese provocaria nas subjetividades um desinvestimento do modo identitário". Uma maneira de se criar universos alternativos, outras vidas.

\section{Referências}

AZZI, Francesca. Aqui ou em todo lugar: apichatpong weerasethakul. In: AZZI, D; AZZI, F. (Org.). Apichatpong Weerasethakul. Trad. Alcione C. Silveira. São Paulo: Iluminuras, 2014. p. 18-25.

CASTRO, Eduardo Viveiro de. O nativo relativo. Mana, Rio de Janeiro, v. 8, n. 1, p. 113148. 2002.

\footnotetext{
${ }^{7} \mathrm{O}$ cinema líquido de Apichatpong, p.95.
} 
CASTRO, Eduardo Viveiro de. Metafísicas canibais: elementos para uma antropologia pósestrutural. São Paulo: Cosac Naify; n-1, 2015.

CUTLER, Aaron; SHELlARD, Mariana. Algumas possíveis vidas de Apichatpong Weerasethakul. In: AZZI, D; AZZI, F. (Org.). Apichatpong Weerasethakul. Trad. Alcione C. Silveira. São Paulo: Iluminuras, 2014. p. 64-71.

DELEUZE, Gilles. Três questões sobre Seis vezes dois (Godard). In: DELEUZE, G. Conversações. Trad. Peter Pál Pelbart. 3. ed. 1. reimp. São Paulo: Editora 34, 2013. p. 53-63.

DELEUZE, Gilles. Cinema 2 - a imagem-tempo. Trad. Eloisa A. Ribeiro. São Paulo: Editora 34, 2018.

DELEUZE, Gilles, GUATTARI, Félix. 28 de novembro de 1947 - como criar para si um Corpo sem Órgãos? In: DELEUZE, G. GUATTARI, F. Mil Platôs: capitalismo e esquizofrenia 2, vol. 3. Trad. Aurélio G. Neto. 2. ed. São Paulo: Editora 34, 2013. p. 11-33.

DELEUZE, Gilles, GUATTARI, Félix. O que é a Filosofia? Trad. Bento Prado Jr. E Alberto A. Muñoz. 3. ed. 1. reimp. São Paulo: Editora 34, 2013.

FONSECA, Rodrigo. O cinema líquido de Apichatpong. In: AZZI, D; AZZI, F. (Org.). Apichatpong Weerasethakul. Trad. Alcione C. Silveira. São Paulo: Iluminuras, 2014. p. 90-95.

FOUCAULT, Michel. A loucura, a ausência da obra. In: FOUCAULT, M. Ditos e escritos I: problematização do sujeito: psicologia, psiquiatria e psicanálise. Rio de Janeiro, Forense Universitária, 1999. p. 190-198.

GONÇALVES, Osmar. Introdução. In: GONÇALVES, O (Org.). Narrativas Sensoriais. Rio de Janeiro: Circuito. 2014, p. 9-26.

GRIMBERG, Daniel. Time and time again: the cinematic temporalities of Apichatpong Weerasethakul. Disponível em: http://www.tft.ucla.edu/mediascape/pdfs/Fall2015/Fall2015_pdf_TimeAndTimeAgain.pdf.

Acesso em maio 2020.

MERCER, Nicholas. Between the global and the local: the cultural geopolitics of Apichatpong Weerasethakul's film aesthetics. In: MANAM, S. A. A.; RAHIM, H. A. (Ed.). Linguistics, Literature and Culture: millennium realities and innovative practices in Asia. Newcastle: Cambridge Scholars Publishing, 2012. p. 191-216.

OBJETO misterioso ao meio-dia. Direção: Apichatpong Weerasethakul. Tailândia, Holanda: 9/6 Cinema Factory et al. 2000, 83 min. Disponível em: https://www.youtube.com/watch?v=s6OHz6S0Kec. Acesso em: ago 2019.

ONETO, Paulo Domenech. Geofilosofia e antropofagia: esboço de leitura deleuzo-guatariana do pensamento modernista de Oswald de Andrade. Periferia, Rio de Janeiro, v. 3, n. 1, p. 1-9, jan.-jun. 2011. Disponível em: https://www.e-publicacoes.uerj.br/index.php/periferia/article/view/3408/2335. Acesso em: mai. 2020. 
QUANDT, James. Empurrar e puxar: um intercâmbio com Apichatpong Weerasethakul. In: AZZI, D; AZZI, F. (Org.). Apichatpong Weerasethakul. Trad. Alcione C. Silveira. São Paulo: Iluminuras, 2014. p. 128-140.

ROLNIK, Suely. Esquizoanálise e antropofagia. In: ALLIEZ, E (Org.). Gilles Deleuze: uma vida filosófica. São Paulo: Editora 34, 2000. p. 451-462.

WEERASETHAKUL, Apichatpong. Fantasmas na escuridão. In: AZZI, D; AZZI, F. (Org.). Apichatpong Weerasethakul. Trad. Alcione C. Silveira. São Paulo: Iluminuras, 2014. p. 102-116.

WEERASETHAKUL, Apichatpong. Hotel Mekong. Tailândia, Inglaterra: Illuminations Films. 2012. 61 min. Disponível em: https://www.youtube.com/watch?v=WZ7jCbNN4hY. Acesso em: ago 2019.

WEERASETHAKUL, Apichatpong. Mal dos trópicos. Tailândia, França, Alemanha, Itália: Backup Media et al. 2004, 118 min. Disponível em: https://www.youtube.com/watch?v=xuFLmHx8J20. Acesso em: ago 2019.

WEERASETHAKUL, Apichatpong. Tio Boonmee, que pode recordar suas vidas passadas. Tailândia, Inglaterra, França, Alemanha, Espanha, Holanda: Kick the machine et al. 2010.114 min. Disponível em: https://www.youtube.com/watch?v=6mUXZDoPV7M. Acesso em: ago. 2019. 